\title{
Low toxicity and favorable
}

(a) CrossMark clinical and quality of life impact after non-myeloablative autologous hematopoietic stem cell transplant in Crohn's disease

\author{
Milton Artur Ruiz ${ }^{1,2,3,4^{*}}$, Roberto Luiz Kaiser Jr. ${ }^{1,4}$, Luiz Gustavo de Quadros ${ }^{1,4}$, Lilian Piron-Ruiz ${ }^{1}$ \\ Tatiana Peña-Arciniegas ${ }^{1}$, Mikaell Alexandre Gouvea Faria ${ }^{1,4}$, Rubens Camargo Siqueira ${ }^{1,5}$, Flavio Fontes Pirozzi ${ }^{1}$, \\ Fernanda Soubhia Liedtke Kaiser ${ }^{4}$ and Richard K. Burt ${ }^{6}$
}

\begin{abstract}
Objective: The incidence of adverse events in myeloablative transplant protocols is high in refractory Crohn's disease; this study used low doses of cyclophosphamide. Fourteen patients were submitted to non-myeloablative autologous hematopoietic stem cell transplantation.

Results: The average number of days of anemia (hemoglobin $<10 \mathrm{~g} / \mathrm{dL}$ ) was $5.4 \pm 4.2$ and $14 \pm 2.4$ in the mobilization and conditioning phases, respectively. The mean number of days of neutropenia (neutrophils $<0.5 \times 10^{9} / \mathrm{L}$ ) in the mobilization phase was $1.7 \pm 1.5$ while it was $7.6 \pm 1.4$ in the conditioning phase. When comparing the conditioning and mobilization phases, there was an increased number days of leukopenia (white blood cells $<1.0 \times 10^{9} / \mathrm{L}$ ), lymphocytopenia (lymphocytes $<0.5 \times 10^{9} / \mathrm{L}$ ) and thrombocytopenia (platelets $<25 \times 10^{9} / \mathrm{L}$ ). Crohn's Disease Activity Index values before the transplant ranged from 155 to 450.5 (mean $281.2 \pm 79.0$ ) and at 30 days after the procedures they ranged from 45.4 to 177 (mean $95.8 \pm 35.4$ ). Moreover, the procedure improved in overall quality of life of patients. Non-myeloablative autologous hematopoietic stem cell transplantation with lower doses of cyclophosphamide leads to lower rates of hematological toxicity and adverse events compared to protocols described in the literature.

Trial registration NCT 03000296: Date 9 December 2016
\end{abstract}

\section{Introduction}

Crohn's disease is a chronic, idiopathic condition with high prevalence and annual incidence from 5.0 to 20.2 per 100,000 person-years [1, 2]. Approximately $80 \%$ of all patients require intestinal surgery including permanent stomas, and many develop tumors [3-5]. Therapy includes anti-inflammatory drugs,

\footnotetext{
*Correspondence: milruiz@yahoo.com.br

${ }^{1}$ Associação Portuguesa de Beneficência, St. Catarina Nucci Parise 760-SJ Rio Preto, Sao Jose Do Rio Preto, SP 15090 470, Brazil

Full list of author information is available at the end of the article
}

steroids, immunosuppressants and biological agents $[6$, 7]. Patients with refractory disease should undergo nonconventional therapies such as autologous hematopoietic stem cell transplantation (aHSCT) [8].

However, transplantation has limited effectiveness with several possible complications, including reduced organ function and infections, and it is not considered standard treatment for Crohn's disease [9].

Nearly all patients in the Autologous Stem Cell Transplantation International Crohn's Disease (ASTIC) trial experienced non-serious adverse events [10]. 
Most complications were related to myeloablation during the conditioning phase including irreversible bone marrow failure, which might be attributed to the high doses of cyclophosphamide used for mobilization [11]. Consequently, non-myeloablative aHSCT regimens have been explored.

This study describes the preliminary results of 14 patients in a larger study. The patients were diagnosed with refractory Crohn's disease and submitted to a non-myeloablative regimen with low doses of cyclophosphamide.

\section{Main text Methods}

This study describes the baseline conditions, treatment protocols, and clinical outcomes of 14 patients diagnosed with Crohn's disease. All patients underwent aHSCT using low doses of cyclophosphamide during mobilization.

\section{Patients}

Inclusion criteria were Crohn's Disease Activity Index (CDAI) greater than 150, intestinal lesions detected by colonoscopy or capsule endoscopy, disease refractory to treatment, a history of adverse reactions to two biologic agents, conditions preventing additional surgical procedures and risk of a permanent stoma and rectal amputation.

All patients with significant comorbidities, including Hodgkin's lymphoma, chronic myeloid leukemia and liver disease, were excluded, as were patients in remission, and with coexisting psychiatric disorders, infectious diseases, fistulae, ulcerative colitis, or neoplastic disorders.

\section{Mobilization phase}

To safely perform the transplant, our goal was a CD34 ${ }^{+}$ count above $3.5 \times 10^{6} / \mathrm{kg}$. Patients were administered a single dose of cyclophosphamide $(60 \mathrm{mg} / \mathrm{kg}$-Baxter $)$ with Sodium-2 Mercaptoethanesulphonate ((mesna)-60 mg/ kg-Blau Farmaceutica) as prophylaxis. Five days later, granulocyte colony-stimulating factor (G-CSF-10 mcg/ $\mathrm{kg}$ /day-Amgen) was administered and maintained until after peripheral hematopoietic stem cell (PHSC) harvesting. Patients with neutrophil levels below $0.5 \times 10^{9} / \mathrm{L}$ received intravenous cefepime (1 g b.i.d.-Bristol) until the end of harvesting. The PHSC were cryopreserved at $-87^{\circ} \mathrm{C}$ without selection or manipulation. Leukopheresis sessions were daily until the $\mathrm{CD} 34^{+}$cell concentration in the peripheral blood was above $8 / \mathrm{mL}$. At the end of harvesting, patients refrained from major physical activities for 7-10 days until the conditioning phase.

\section{Conditioning phase}

Conditioning consisted of cyclophosphamide $(50 \mathrm{mg} /$ $\mathrm{kg}$ for 4 days) and total dose of $6.5 \mathrm{mg} / \mathrm{kg}$ rabbit antithymocyte globulin (rATG-Genzyme) administered daily for 4 days prior to the PHSC infusion. Methyl prednisolone (Pfizer-500 mg/day) was also administered prior to the rATG to reduce the risk of adverse reactions. Additionally, mesna (50 mg/kg for 4 days) was administered to reduce the risk of toxicity. In cases of neutropenia $\left(<0.5 \times 10^{9} / \mathrm{L}\right)$ occurring between days 1 and $5,10 \mu \mathrm{g} /$ $\mathrm{kg} /$ day of G-CSF was administered after the infusion of PHSC and maintained until the absolute neutrophil and platelet counts reached $0.5 \times 10^{9} / \mathrm{L}$ and $20 \times 10^{9} / \mathrm{L}$, respectively.

\section{Supportive care}

Sulfamethoxazole (400 mg PO-Neoquimica) and trimethoprim (80 mg PO-Neoquimica) were administered three times/day for prophylaxis against Pneumocystis jiroveci during the 4 days prior to the PHSC infusion. Other medications prophylactically administered included ciprofloxacin (500 mg PO b.i.d.-Eurofarma), metronidazole (250 mg PO t.i.d.-Eurofarma), acyclovir (200 mg PO t.i.d.-Teuto) and fluconazole (150 mg PO b.i.d.). Cefepime (1 g IV b.i.d.) was administered if neutropenia occurred. Targocid (400 mg/day IV-Sanofi) was administered if fever reached $38.2{ }^{\circ} \mathrm{C}$ and replaced with meronen ( 2 g IV b.i.d.) if the fever continued. Further episodes of fever were treated with polymyxin B (Eurofarma/Quimiica Haller). Blood samples were collected from the central venous catheter for culturing. Transfusion of red blood cell concentrates was determined by hematocrit values below $25 \%$ and platelet transfusions were indicated when counts were below $20 \times 10^{9} / \mathrm{L}$. Blood components were deleucotized by irradiation prior to transfusion.

\section{Outcomes}

Clinical evaluations were performed before and for up to 30 days after transplantation. This assessment included the CDAI [12], Crohn's Disease Endoscopic Index of Severity (CDEIS) [13], Simple Endoscopic Score for Crohn's Disease (SES-CD) [14], Crohn's Severity Index (CSI), Harvey-Bradshaw index (HBI) [15], and Rutgeerts Score to evaluate the anastomosis after ileocolic resection [16]. The Bristol stool scale was used to categorize frequency and consistency of patients' stools [17]. Toxicity was evaluated according to the National Cancer Institute Common Criteria for toxicity [18], and quality of life (QoL) according to the Short Form-36 (SF-36) [19]. 


\section{Statistical analysis}

Data analysis was descriptive (means, frequencies and percentages) with most results being reported for individual patients. All analyses were performed using the $\mathrm{R}$ language [20] and the ggplot2 [21], rmarkdown [22] packages.

\section{Ethical considerations}

This study registered was as a trial (NCT 03000296: Date 9 December 2016) and reviewed and approved by the Ethics Review Board for Research involving Human Beings of the Hospital da Associacao Portuguesa de Beneficencia Sao Jose do Rio Preto and all patients provided written informed consent.

\section{Results}

Seven male and seven female patients were evaluated with a mean age of 35.9 years (range $24-50$ years). Details about the patient demographics and clinical manifestations prior to aHSCT are shown in Additional file 1.

\section{Patient outcomes}

Eleven patients were classified using the CDEIS and SESCD scores while seven were classified using Rutgeerts scale. Two patients did not follow any of the above classifications given a history of extensive resection surgeries, although they were diagnosed as having Crohn's disease through entero-resonance and/or capsule endoscopy. Table 1 shows the classification of patients according to the different scores.
CDAI scores 30 days after the procedure ranged from 45.4 to 177.0 (mean $95.8 \pm 35.4$ ). Thirteen patients presented CDAI scores below 150 within 30 days after the transplant.

\section{Crohn's disease kinetics}

The mean number of cells collected during leukapheresis was $13.4 \times 10^{6} \pm 9.5 \times 10^{6} / \mathrm{kg}\left(\right.$ range $\left.4.3-36.7 \times 10^{6}\right)$ with no adverse reactions being reported, which demonstrated that all patients presented good mobilization. After the PHSC infusion, all patients reported taste modifications, abdominal discomfort and dark urine at the first urination. Patients took an average of 9.8 days to obtain neutrophil levels greater than $0.5 \times 10^{9} / \mathrm{L}$. A similar period was observed to reach platelet counts above $25 \times 10^{9} / \mathrm{L}$.

Data on Crohn's disease kinetics during mobilization and conditioning are shown in Table 2.

\section{Complications}

All patients presented with diarrhea during the mobilization phase (mean days $13.6 \pm 5.1$ ). The frequency increased when the patient had neutropenia during the conditioning phase (average days of diarrhea 17.2 \pm 3.7 ). Digestive symptoms improved after the mobilization phase with a progressive reduction in diarrheal episodes until symptoms disappeared.

An additional table lists complications following HSCT (see Additional file 2) and hematological abnormalities during conditioning and mobilization are shown in Additional file 3 .

Table 1 Scores prior to autologous hematopoietic stem cell transplantation

\begin{tabular}{|c|c|c|c|c|c|c|c|}
\hline Patient\# & $\mathrm{HBI}$ & CSI & Montreal & CDEIS & SES-CD & Rutgeerts & CDAI \\
\hline 1 & 37 & 30 & A2 L4 B2 & 17 & 18 & i4 & 450.5 \\
\hline 2 & 18 & 22 & A3 L3 B2 & 6 & 8 & - & 247 \\
\hline 3 & 22 & 20 & A1 L3 B1 & 11 & 14 & - & 306 \\
\hline 4 & 48 & 35 & A1 L1 B1 & - & - & - & 427 \\
\hline 5 & 15 & 28 & A2 L3 B2 & 1 & 4 & - & 240 \\
\hline 6 & 14 & 23 & A2 L3 B1 & 7 & 6 & i4 & 250 \\
\hline 7 & 15 & 32 & A2 L3 B1p & 15 & 22 & - & 261 \\
\hline 8 & 14 & 20 & A2 L3 B2 & 14 & 14 & i4 & 273.7 \\
\hline 9 & 21 & 31 & A3 L3 B3p & - & - & - & 308 \\
\hline 10 & 22 & 28 & A3 L3 B3p & 8 & 7 & i4 & 260 \\
\hline 11 & 16 & 16 & A2 L3 B2 & 10 & 13 & i4 & 284.8 \\
\hline 12 & 13 & 36 & A2 L3 B2P & 36 & 24 & i4 & 287.5 \\
\hline 13 & 14 & 34 & A2 L3 B2 & 34 & 11 & i4 & 186 \\
\hline 14 & 11 & 17 & A1 L3 B2P & - & - & - & 155 \\
\hline Mean \pm SD & $20 \pm 10.3$ & $26.5 \pm 6.8$ & & $14.5 \pm 11.1$ & $12.8 \pm 6.5$ & & 281.2 \\
\hline
\end{tabular}

HBI Harvey-Bradshaw index; CSI Crohn's severity index; CDEIS Crohn's disease endoscopic index of severity; SES-CD simple endoscopic score for Crohn's disease; CDAI Crohn's disease activity index; $S D$ standard deviation 
Table 2 Crohn's disease kinetics during mobilization and conditioning phases

\begin{tabular}{|c|c|c|c|c|c|c|}
\hline Patient\# & $\begin{array}{l}\text { CD34+ harvested } \\
\text { and infused }\left(\times 10^{6}\right)\end{array}$ & $\begin{array}{l}\text { Number } \\
\text { of apheresis ses- } \\
\text { sions }\end{array}$ & $\begin{array}{l}\text { Neutrophil graft } \\
\text { day }\end{array}$ & Platelet graft day & $\begin{array}{l}\text { Number of units } \\
\text { of RBCs (mobiliza- } \\
\text { tion/ conditioning) }\end{array}$ & $\begin{array}{l}\text { Number of units } \\
\text { of platelets (mobili- } \\
\text { zation/ conditioning) }\end{array}$ \\
\hline 1 & 4.59 & 2 & 7 & 7 & $0 / 0$ & $0 / 0$ \\
\hline 2 & 8.52 & 2 & 9 & 9 & $0 / 0$ & $0 / 0$ \\
\hline 3 & 7.4 & 2 & 9 & 9 & $0 / 2$ & $0 / 0$ \\
\hline 4 & 5.07 & 1 & 10 & 10 & $0 / 1$ & $0 / 0$ \\
\hline 5 & 4.3 & 1 & 12 & 12 & $0 / 2$ & $0 / 1$ \\
\hline 6 & 7.7 & 2 & 10 & 10 & $0 / 2$ & $0 / 2$ \\
\hline 7 & 10.2 & 2 & 10 & 10 & $0 / 7$ & $0 / 2$ \\
\hline 8 & 8.1 & 1 & 10 & 10 & $0 / 2$ & $0 / 4$ \\
\hline 9 & 22 & 1 & 9 & 9 & $0 / 2$ & $0 / 1$ \\
\hline 10 & 18.67 & 1 & 11 & 11 & $0 / 2$ & $0 / 5$ \\
\hline 11 & 36.65 & 2 & 11 & 11 & $2 / 11$ & $0 / 3$ \\
\hline 12 & 22.3 & 1 & 9 & 9 & $1 / 1$ & $0 / 0$ \\
\hline 13 & 19.7 & 1 & 10 & 10 & $1 / 2$ & $0 / 3$ \\
\hline 14 & 20 & 1 & 10 & 10 & $0 / 4$ & $0 / 3$ \\
\hline
\end{tabular}

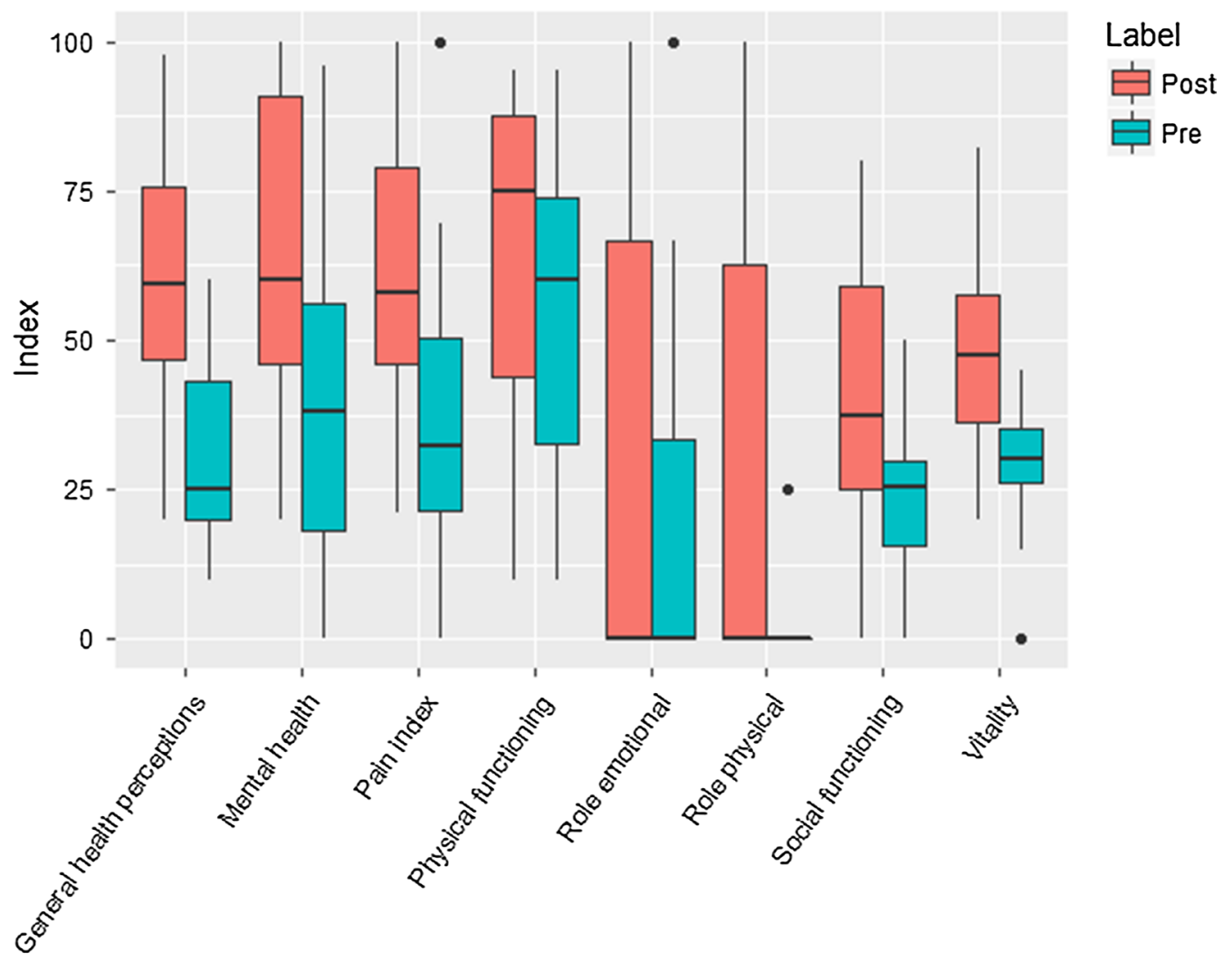

Variable

Fig. 1 Quality of life, variable means before and after aHSCT 


\section{Quality of life}

An overall improvement in the different SF-36 domains was observed after aHSCT (Fig. 1).

\section{Discussion}

This study describes a non-myeloablative regimen for aHSCT with low doses of cyclophosphamide during mobilization. Clinical outcomes 30 days after aHSCT were better than published results. Prior to the procedure, all patients presented CDAIs $>150$ whereas 30 days after aHSCT, 13 patients were in remission with CDAIs $<150$. This non-myeloablative protocol resulted in low toxicity with only four patients having complications directly related to the transplant.

The protocol of published studies consisted of a conditioning regimen with anti-lymphocyte globulin or total body irradiation followed by the infusion of PHSC collected by apheresis [23]. Early ablative regimens presented high toxicity without improving clinical outcomes compared to the standard Crohn's disease treatment [8]. Contrary to the current study with substantial improvements within 1 month, the first aHSCT case series involving four patients with Crohn's disease resulted in an improvement in CDAI scores 3 months after procedure [8] with three of the four patients presenting unexpected adverse events (perianal abscess after mobilization, pleural and pericardial effusions, and macro-hematuria). In a subsequent case series involving 12 patients, nearly all presented with hematological abnormalities, neutropenic fever, disease-related fever, diarrhea, anorexia, nausea and vomiting [24]. In addition, the median days for neutrophil and platelet engraftment were 9.5 (range 8-11) and 9 (range 9-18), respectively, compared to 1.5 (range $0-4$ ) and 0.0 (range $0-1$ ) days in the current study.

Non-myeloablative regimens have been designed to reduce the time of neutropenia and immunosuppression [11]. Cyclophosphamide was previously used at doses of $4 \mathrm{~g} / \mathrm{m}^{2}$ [26], $2 \mathrm{~g} / \mathrm{m}^{2}$ for 2 days [10, 27] and $2 \mathrm{~g} / \mathrm{m}^{2}$ for 4 days [11] during mobilization. In contrast, this study used $50-60 \mathrm{mg} / \mathrm{kg} /$ day $\left(2 \mathrm{~g} / \mathrm{m}^{2}\right)$ of cyclophosphamide administered over 1 day. The better outcomes reported here might be explained by the lower doses of cyclophosphamide during mobilization.

In one study involving 26 patients, mobilization, with a median duration of 5 days (range 2-7), resulted in the following complications: febrile neutropenia (16 patients), bacteremia (one patient) and septic shock (two patients). Other complications included acute renal failure in one patient with septic shock, pharmacodermia following the use of vancomycin, and anemia. Approximately $80 \%$ of all patients required transfusions after their hemoglobin levels dropped below $12 \mathrm{~g} / \mathrm{dL}$ and only 21 patients proceeded to the conditioning and transplantation phases. The mean time before starting conditioning after leucopheresis was 53 days (range 14-458), and neutropenia and thrombocytopenia lasted for a median of 11 (range 7-16) and 4 days (range 2-8), respectively. During the conditioning phase, 20 patients (95\%) presented febrile neutropenia, one presented with septic shock, perianal lesions worsened in three patients, and all patients required transfusions. This case series also described non-infectious complications in six cases (29\%), including reactions to the use of $\mathrm{rATG}$ with severe hypotension, and $12(57 \%)$ patients presenting with mucositis (Berman grades I-II) [25]. Conversely, during the mobilization phase of the current study, febrile neutropenia was observed in one patient (7\%), no patient presented bacteremia or septic shock and only three patients (21\%) required blood transfusions. In the conditioning phase, four patients (29\%) presented with febrile neutropenia with confirmed evidence of bacteremia, with 13 (93\%) patients requiring blood transfusions. In contrast to our protocol, the ASTIC study [10] used twice the dose of cyclophosphamide during the mobilization phase $(4 \mathrm{~g} /$ $\mathrm{m}^{2}$ ). Our group has previously suggested that this dosage was high for mobilization, ultimately leading to toxicity [26]. In fact, the ASTIC study reported frequent serious adverse events (79 in 19 patients) with nearly all patients experiencing non-serious adverse events. However, no serious adverse events were reported, while non-serious adverse events were observed in all patients. In the study by Burt [11], 11 patients (46\%) presented with infectious complications during hospitalization, while in this study only three (21\%) patients presented with infectious complications. Besides the different dosage, the higher rates of complications in the ASTIC trial might be explained because it was multicentric, where compliance with the protocol might vary across sites.

As far as we know, this study is the first to evaluate early QoL following aHSCT. Previous studies have demonstrated poor functional outcomes in patients with severe active Crohn's disease including psychosocial dysfunction, addiction to narcotics, decreased productivity and reduced QoL scores [27]. However, remission in this condition is associated with improved function including QoL [28]. This is consistent with findings of this study where there was an overall improvement in all SF-36 domain scores after remission.

The current study demonstrates lower hematological toxicity with fewer infectious complications and adverse events following aHSCT compared to previous studies. We therefore recommend that future studies should consider the use of lower doses of cyclophosphamide in mobilization regimens. 


\section{Limitations}

This study has limitations frequently associated with case series. First, there was no control group, which precludes comparisons with traditional, ablative treatments. Second, the sample size is small, not allowing for the evaluation of risk factors. Last, this is a single-center study, and so the effect of multiple centers on outcomes cannot be determined.

\section{Additional files}

Additional file 1. Sociodemographic and clinical characteristics.

Additional file 2. Complications following autologous hematopoietic stem cell transplantation.

Additional file 3. Hematological abnormalities during autologous hematopoietic stem cell transplantation.

\section{Abbreviations}

mesna: Sodium-2-Mercaptoethanesulphonate; PHSC: peripheral hematopoietic stem cells; AGA: American Gastroenterological Association's; ATG: antithymocyte globulin; aHSCT: autologous hematopoietic stem cell transplantation; ASTIC: Autologous Stem Cell Transplantation International Crohn's Disease; CDAl: Crohn's disease activity index; CDEIS: Crohn's disease endoscopic index of severity; CSI: Crohn's severity index; G-CSF: granulocyte colony-stimulating factor; HBI: Harvey-Bradshaw index; PO: per os; SF-36: Short Form-36; SES-CD: Simple Endoscopic Score for Crohn's Disease; QoL: quality of life.

\section{Authors' contributions}

All authors participated in drafting of the manuscript or critical revision of the manuscript for important intellectual content. Individual contributions are as follows: MAR: conception and design; analysis and interpretation of data; drafting and reviewing of the manuscript. RLKJ and LGDQ: conception and design. LPR and TPA: analysis and interpretation of data; drafting and reviewing of the manuscript. MAGF, RCS and FFP: reviewing of the manuscript. FSLK: analysis and interpretation of data. RKB: analysis and interpretation of data; reviewing of the manuscript . All authors read and approved the final manuscript.

\section{Author details}

${ }^{1}$ Associação Portuguesa de Beneficência, St. Catarina Nucci Parise 760-SJ Rio Preto, Sao Jose Do Rio Preto, SP 15090 470, Brazil. 2 Faculdade de Medicina da Universidade de São Paulo, São Paulo, SP, Brazil. ${ }^{3}$ Departamento de Genética Unesp/lbilce Sao Jose do Rio Preto, Sao Jose Do Rio Preto, SP, Brazil. ${ }^{4}$ Kaiser Clinica, Sao Jose Do Rio Preto, SP, Brazil. ${ }^{5}$ Faculdade de Medicina da Universidade de São Paulo, Ribeirão Preto, São Paulo, SP, Brazil. ${ }^{6}$ Division of Immunotherapy, Northwestern University Feinberg School of Medicine, Chicago, IL, USA.

\section{Acknowledgements}

Not applicable.

\section{Competing interests}

The authors declare that they have no competing interests.

\section{Availability of data and materials section}

Data on Sociodemographic and clinical characteristics, Complications following autologous hematopoietic stem cell transplantation and Hematological abnormalities during autologous hematopoietic stem cell transplantation are provided in additional supporting files submitted with this manuscript. Any further information is available from the corresponding author on reasonable request.

\section{Consent for publication}

Not applicable.

\section{Ethics approval and consent to participate}

This study registered was as a trial (NCT 03000296: Date 9 December 2016) and reviewed and approved by the Ethics Review Board for Research involving Human Beings of the Hospital da Associacao Portuguesa de Beneficencia Sao Jose do Rio Preto (Reference Number: 1.233.124). This research was performed in accordance with the Declaration of Helsinki and all patients provided written informed consent.

\section{Funding}

None.

\section{Publisher's Note}

Springer Nature remains neutral with regard to jurisdictional claims in published maps and institutional affiliations.

Received: 20 December 2016 Accepted: 30 September 2017

Published online: 06 October 2017

\section{References}

1. Loftus EV. Clinical epidemiology of inflammatory bowel disease: incidence, prevalence, and environmental influences. Gastroenterology. 2004:126:1504-17.

2. Molodecky NA, Soon S, Rabi DM, Ghali WA, Ferris M, Chernoff G, et al. Increasing incidence and prevalence of the inflammatory bowel diseases with time, based on systematic review. Gastroenterology. 2012;142:46-54.

3. Cosnes J, Gower-Rousseau C, Seksik P, Cortot A. Epidemiology and natural history of inflammatory bowel diseases. Gastroenterology. 2011;140:1785-94.

4. Bernstein CN, Blanchard JF, Kliewer E, Wajda A. Cancer risk in patients with inflammatory bowel disease. Cancer. 2001;91:854-62.

5. von Roon AC, Reese G, Teare J, Constantinides V, Darzi AW, Tekkis PP. The risk of cancer in patients with crohn's disease. Dis Colon Rectum. 2007;50:839-55.

6. Terdiman JP, Gruss CB, Heidelbaugh JJ, Sultan S, Falck-Ytter YT. American Gastroenterological Association Institute Guideline on the use of thiopurines, methotrexate, and anti-TNF-a biologic drugs for the induction and maintenance of remission in inflammatory Crohn's disease. Gastroenterology. 2013;145:1459-63.

7. Baumgart DC, Sandborn WJ. Crohn's disease. Lancet. 2012;380:1590-605.

8. Cassinotti A, Annaloro C, Ardizzone S, Onida F, Volpe AD, Clerici M, et al. Autologous haematopoietic stem cell transplantation without CD34 ${ }^{+}$cell selection in refractory Crohn's disease. Gut. 2008;57:211-7.

9. Daikeler T, Tichelli A, Passweg J. Complications of autologous hematopoietic stem cell transplantation for patients with autoimmune diseases. Pediatr Res. 2012;71:439-44.

10. Hawkey CJ, Allez M, Clark MM, Labopin M, Lindsay JO, Ricart E, et al. Autologous hematopoetic stem cell transplantation for refractory Crohn disease: a randomized clinical trial. JAMA. 2015;314:2524-34.

11. Burt RK, Craig RM, Milanetti F, Quigley K, Gozdziak P, Bucha J, et al. Autologous nonmyeloablative hematopoietic stem cell transplantation in patients with severe anti-TNF refractory Crohn disease: long-term followup. Blood. 2010;116:6123-32.

12. Thia K, Faubion WA, Loftus EV, Persson T, Persson A, Sandborn WJ. Short CDAl: development and validation of a shortened and simplified Crohn's disease activity index. Inflamm Bowel Dis. 2011;17:105-11.

13. Mary J-Y, Modigliani R. Development and validation of an endoscopic index of the severity for Crohn's disease: a prospective multicentre study. groupe d'Etudes therapeutiques des affections inflammatoires du tube digestif (GETAID). Gut. 1989;30:983-9.

14. Daperno M, D'Haens G, Van Assche G, Baert F, Bulois P, Maunoury V, et al. Development and validation of a new, simplified endoscopic activity score for Crohn's disease: the SES-CD. Gastrointest Endosc. 2004:60:505-12. 
15. Harvey R, Bradshaw J. A simple index of Crohn's-disease activity. Lancet. 1980:315:514

16. Blazquez I, Gonzalez-Lama Y, Suarez C, Matallana V, Calvo M, Isabel V, et al. DOP034 Rutgeerts score and endoscopy based management of postoperative Crohn's disease are useful in patients already receiving pharmacological treatment for recurrence prevention. J Crohns Colitis. 2014;8:S31.

17. Riegler G, Esposito I. Bristol scale stool form a still valid help in medical practice and clinical research. Tech Coloproctol. 2001;5:163-4.

18. Trotti A, Byhardt R, Stetz J, Gwede C, Corn B, Fu K, et al. Common toxicity criteria: version an improved reference for grading the acute effects of cancer treatment: Impact on radiotherapy. Int J Radiat Oncol Biol Phys. 2000;47:13-47.

19. Anderson C, Laubscher S, Burns R. Validation of the short form 36 (SF-36) health survey questionnaire among stroke patients. Stroke. 1996:27:1812-6.

20. R Core Team. R: A language and environment for statistical computing. Vienna: R Foundation for Statistical Computing; 2015. http://www.Rproject.org/.

21. Wickham H. Ggplot2: Elegant graphics for data analysis. Berlin: Springer; 2009
22. Allaire J, Cheng J, Xie Y, McPherson J, Chang W, Allen J, et al. Rmarkdown: dynamic documents for R. 2015. http://CRAN.R-project.org/ package $=$ rmarkdown.

23. Marmont AM. Stem cell transplantation for severe autoimmune diseases: progress and problems. Haematologica. 1998;83(8):733-43.

24. Oyama Y, Craig RM, Traynor AE, Quigley K, Statkute L, Halverson A, et al. Autologous hematopoietic stem cell transplantation in patients with refractory crohn's disease. Gastroenterology. 2005;128:552-63.

25. Jauregui-Amezaga A, Rovira M, Marín P, Salas A, Pinó-Donnay S, Feu F, et al. Improving safety of autologous haematopoietic stem cell transplantation in patients with Crohn's disease. Gut. 2016:65(9):1456-62.

26. Burt RK, Ruiz MA, Kaiser RL. Stem cell transplantation for refractory crohn disease. JAMA. 2016;315:2620.

27. Hommes DW, Lacey PN. Stem cells: HSCT for Crohn's disease: work in progress or a bridge too far? Nature reviews. Nat Rev Gastroenterol Hepatol. 2016:13:128-30.

28. Lichtenstein GR, Yan S, Bala M, Hanauer S. Remission in patients with Crohn's disease is associated with improvement in employment and quality of life and a decrease in hospitalizations and surgeries. Am J Gastroenterol. 2004;99:91-6.

\section{Submit your next manuscript to BioMed Central and we will help you at every step:}

- We accept pre-submission inquiries

- Our selector tool helps you to find the most relevant journal

- We provide round the clock customer support

- Convenient online submission

- Thorough peer review

- Inclusion in PubMed and all major indexing services

- Maximum visibility for your research

Submit your manuscript at www.biomedcentral.com/submit
() Biomed Central 